University of Nebraska - Lincoln

DigitalCommons@University of Nebraska - Lincoln

Sociology Department, Faculty Publications

Sociology, Department of

2020

Unpacking the black box of survey costs

Kristen M. Olson

University of Nebraska - Lincoln, kolson5@unl.edu

Follow this and additional works at: https://digitalcommons.unl.edu/sociologyfacpub

Part of the Family, Life Course, and Society Commons, Quantitative, Qualitative, Comparative, and Historical Methodologies Commons, and the Social Psychology and Interaction Commons

Olson, Kristen M., "Unpacking the black box of survey costs" (2020). Sociology Department, Faculty Publications. 738.

https://digitalcommons.unl.edu/sociologyfacpub/738

This Article is brought to you for free and open access by the Sociology, Department of at DigitalCommons@University of Nebraska - Lincoln. It has been accepted for inclusion in Sociology Department, Faculty Publications by an authorized administrator of DigitalCommons@University of Nebraska - Lincoln. 


\title{
Unpacking the black box of survey costs
}

\author{
Kristen Olson \\ University of Nebraska-Lincoln, Department of Sociology, \\ 703 Oldfather Hall Lincoln, NE, 68588-0324, USA
}

\begin{abstract}
Survey costs are a critically important input to and constraint on the quality of data collected from surveys. Much about survey costs is unknown, leading to lack of understanding of the drivers of survey costs, the relationship between survey costs and survey errors, and difficulty in justifying the importance of survey data versus other available administrative or organic data. This commentary outlines a recently developed typology for survey costs, illustrates this typology using methodological articles that report on costs in pharmacy surveys, and provides recommendations for research on the relationship between fixed and variable costs as a major area for further reporting and research, as well as the relationship between costs and errors.
\end{abstract}

Keywords: Survey research, Survey costs

\section{Introduction}

Well-conducted surveys attempt to maximize survey quality, produce results in a timely manner, and make survey results available to those who need them. ${ }^{1}$ Each of these decisions is constrained by available resources, commonly referred to as survey costs. ${ }^{2}$ Survey researchers and methodologists frequently face questions when designing studies about

Published as: Kristen Olson, Research in Social and Administrative Pharmacy, https://doi. org/10.1016/j.sapharm.2020.08.014

Copyright (C) 2020 Elsevier Inc. Used by permission.

Submitted 31 May 2020; revised 21 August 2020; accepted 22 August 2020; published 28 August 2020. 
whether certain design features are cost-effective. These design features range from the use of different levels of prepaid incentives ${ }^{3}$ to switching from interviewer-administered to self-administered modes of data collection ${ }^{4}$ to translating instruments into multiple languages. ${ }^{5}$ Survey researchers also wonder whether certain subpopulations are more expensive to study than others, whether costs are higher in different regions of the United States, for different age groups, or for household versus establishment-based surveys. Pharmacy studies face similar cost and design feature decisions. Survey research methods are common in pharmacy studies ${ }^{6,7}$; a recent review found that about one-half of all articles published in major pharmacy journals in 2016 used some kind of survey methods. ${ }^{8}$

Yet how different design features in surveys affect costs, how costs vary across different types of studies, and whether costs are related to survey errors is not well-understood. Although survey quality can draw on the Total Survey Error framework ${ }^{1,2,9}$ for understanding, survey costs are much more of a black box, with costs often considered to be proprietary, not tracked at levels that are useful for analysis, or difficult to extract from an organization's records. Yet those who conduct surveys are constantly reacting to changing technological and social environments for instance, adding or changing modes of data collection, linking to administrative records or collecting biomarkers, adding questions in order to more fully capture a phenomenon, or shortening questionnaires to reduce perceptions of burden. Each of these design changes has cost implications, both for the overall budget as well as cost per sampled unit and cost per responding unit. Although there are general perceptions about shifts in cost structures with changes in design, systematic empirical data about how costs vary with data collection changes are scant.

The difficulty in identifying cost parameters has long been recognized even within institutions, either because record systems do not keep track of costs or because survey researchers tend to not analyze cost data as they do survey data or error indicators. Leslie Kish, ${ }^{10}$ in his classic sampling textbook, reported "to choose the most economical design we must also consider (estimate, guess, or assume) some cost factors" (italics added; p. 267). It is notable how little has changed in systematic knowledge about costs since 1965. In a meta-analysis examining the effects of incentives on response rates, Singer and colleagues ${ }^{11}$ (p. 225) comment that "The biggest deficiency in these studies [included 
in the meta-analysis] is the absence of data on the costs of surveys with and without incentives." Similarly, Valliant, Dever, and Kreuter ${ }^{12}$ (p. 231) note "... tracking these costs is difficult and often does not mesh well with survey accounting practices. As a result, you may have to be satisfied with fairly rough unit cost estimates." A 2006 workshop held by the National Institute for Statistical Sciences ${ }^{13}$ on survey costs noted an urgent need for more work on costs, with a limitation being "the need to construct quantifiable indicators of cost and quality" (p. 13), as well as “... a strong sense that immense knowledge about surveys [costs], both quantified ... and anecdotal, resides in the organizations that carry out survey data collections. How to access this knowledge by engaging such organizations in the research was much less clear" (p. 16). Thus, drivers of actual survey costs for different parts of the survey process and variation in survey costs over sample units are largely unknown or uncertain, as is the association between survey costs and survey errors.

To answer the questions of "what do different types of surveys cost," "does including design feature X (e.g., prepaid incentives, advance letters, experienced interviewers) reduce survey costs," and "do more expensive surveys yield lower survey errors," unified measures of costs that can be compared across study designs and populations are needed. For these cost measures to be useful, costs themselves need to be treated as a measurement problem, with clear articulation of the inputs and assumptions for the cost measurements. This commentary outlines a recently developed typology for survey costs, illustrates this typology using methodological articles that report on costs in pharmacy surveys, identifies the relationship between fixed and variable costs and the relationship between costs and errors as areas for research, and presents concluding recommendations.

\section{A recently developed typology of survey costs}

One challenge in understanding how survey costs vary across studies, across design features, and across subpopulations is that different studies report costs in different units of measurement. To address this challenge, Olson, Wagner, and Anderson ${ }^{14}$ recently developed a typology of survey costs which groups measures of survey costs into categories: (1) costs for the full study or for individual survey components, (2) currency 
of the country conducting the survey (denoted $C$ ) versus non-currency costs (e.g., full-time equivalent staff; number of hours, denoted $\int$ ), and (3) costs measured as totals, costs per units, and relative costs. Each of these costs is conditional on the time of measurement $(t)$, where time is broadly operationalized as calendar time (year, month), wave of a longitudinal survey, or time during the data collection field period. Survey components are defined as mutually exclusive and exhaustive sets of design features that affect both fixed (costs that do not vary with sample size) and variable (costs that do vary with sample size) costs; the total overall costs of a survey is the sum of the costs of the components.

Furthermore, some costs may be measured in accounting systems, and are thus referred to as observed costs (denoted $O$ ); other costs may arise from pre-data collection budgets and are thus estimated costs (denoted $E$ ); finally, the costs that are actually incurred are actual costs (denoted $A$ ), which may deviate from both the initial budget as well as what is measured in the accounting system. This distinction is important - costs that are incurred but do not appear in accounting systems cannot be measured easily, even if they appear in budgets. Discrepancies between these sources of costs also are meaningful - for instance, differences between estimated costs and observed costs lead to projects being under- or over-budget, and are routinely monitored by survey organizations. Differences between observed and actual costs - for example, an interviewer works on two projects but does not disentangle the hours worked on these projects in their timesheet - results in projects not being able to accurately monitor costs or adjust budgets for future data collections.

Thus, following the notation from Olson, Wagner, and Anderson, ${ }^{14}$ the costs for an individual survey component (i) as measured in the records $(O)$ at time $t$ in a currency metric is denoted as $C^{O}{ }_{i t}$, and the total cost for a survey in currency metrics is the sum over all of the components $i$ for the study. The cost per unit for a component divides this cost by the sample size $n\left(C^{o}{ }_{i t} / n\right)$ or the respondent size $r\left(C_{i t}^{o} / r\right)$, and relative costs are ratios of these costs over different components, different times, or different experimental treatments. The analogous costs measured in non-currency metrics, such as the number of full-time equivalent staff, the number of hours charged by interviewers, or the total number of call attempts, can be written with $J_{i t}^{0}$. Costs that come from a budget estimate rather than records are denoted with a superscript E 
$\left(C^{E}{ }_{i t} J^{E}{ }_{i t}\right)$ and those that are actual costs, perhaps from a special tracking study, are denoted with a superscript A $\left(C^{A}{ }_{i t}, J^{A}{ }_{i t}\right)$.

Similar to the AAPOR Standard Definitions ${ }^{15}$ for response rates, this typology can be used to categorize types of survey costs to be used as both outcomes (what predicts variation in survey costs) and as predictors (how do costs relate to survey errors). The next section illustrates this typology and the range of cost measures and components that are used in published cost reports.

\section{Examples of survey costs reported in pharmacy studies}

Table 1 contains cost information reported in four studies published in Research in Social and Administrative Pharmacy. Each of these surveys has a similar target population (pharmacists or pharmacies) and used mail to recruit sample members, with different modes for participation (e.g., telephone, web, and mail). These studies report both monetary and nonmonetary costs for surveys, total costs, costs per sample unit, and costs per responding unit, as well as useful details about the components used for the cost calculations. These four papers provide illustrative models for the typology of monetary and nonmonetary survey costs.

Westrick and Mount (2007) ${ }^{16}$ examines monetary and nonmonetary costs for a mail survey with (estimated) costs for a telephone follow-up with and without an advance letter, reporting both costs per sample unit and costs per complete. In this study, the per-unit costs for a postcardlength mail survey include mail out and return postage, printing, envelopes, incentives, and 10 hours of labor $\left({ }^{O}{ }_{i t}\right)$ for arranging the mailing with only one mailed contact attempt is $\$ 1.20$ per sampled unit $\left(C^{0}{ }_{i t} / n\right)$, and $\$ 4.37$ per completed respondent $\left(C^{O}{ }_{i t} / r\right)$. A small subset of nonrespondents were contacted by telephone, and the authors estimated the costs for this telephone follow-up, and then estimated the costs for mailing advance materials versus not mailing advance materials, assuming no change in response rate with or without advance materials. The authors report nonmonetary costs for the telephone follow-up; in particular, interviewers spend 1368 minutes on interviewing $\left(U_{i t}^{o}\right)$, an average of 10 minutes total per complete for respondents ( 5 minutes 32 seconds on interviewing itself, $\left(J_{i t}^{O} / r\right.$ ) and 5 minutes ( 1 minute 27 seconds on interviewing itself, $\left.U_{i t}^{o} / n r\right)$ per nonrespondents, aggregating to a total of 
Table 1. Survey costs as reported in four Research in Social and Administrative Pharmacy papers.

\begin{tabular}{|c|c|c|c|c|}
\hline & $\begin{array}{l}\text { Westrick and } \\
\text { Mount (2007) }\end{array}$ & $\begin{array}{l}\text { Hardigan, Popvici, } \\
\text { Carvajal (2016) }\end{array}$ & $\begin{array}{l}\text { Schherbakova } \\
\text { (2016) }\end{array}$ & $\begin{array}{l}\text { Agley et al. } \\
\text { (2017) }\end{array}$ \\
\hline $\begin{array}{l}\text { Sample size and } \\
\text { response rate }\end{array}$ & $\begin{array}{l}\text { Mail: } 1143 ; 26.7 \% \\
\text { Telephone FU: } 262 ; 83.6 \%\end{array}$ & $\begin{array}{l}\text { 7200; Mail: } 21.0 \% \\
\text { Email: } 6.8 \% \\
\text { Mail postcard with } \\
\text { web link: } 3.2 \%\end{array}$ & $5044 ; 1.7 \%$ & $993 ; 32.9 \%$ \\
\hline Components & $\begin{array}{l}\text { Mail: Cover letter +"postcard } \\
\text { length survey" + study } \\
\text { description + letter of support } \\
\text { + promised lottery incentive } \\
\text { Telephone follow-up: } \\
\text { Weekday afternoon calling } \\
\text { for } 4 \text { weeks; } \\
\text { Request for pharmacy manager } \\
\text { or pharmacist on duty; } \\
3 \text { contact attempts; } \\
\text { No incentives }\end{array}$ & $\begin{array}{l}\text { Mail: Cover letter + } \\
\text { questionnaire + SASE } \\
\text { + Refusal postcard } \\
\text { Replacement } \\
\text { questionnaire } \\
\text { Reminder postcard } \\
\text { Email: Email message } \\
\text { with link and refusal link } \\
\text { Reminder email with } \\
\text { survey link and } \\
\text { refusal link } \\
\text { Reminder email } \\
\text { Hybrid: Mailed postcard } \\
\text { with web link and } \\
\text { refusal link } \\
\text { Mailed Reminder postcard }\end{array}$ & $\begin{array}{l}\text { Mailed postcard } \\
\text { with web link } \\
\text { ("hybrid”) } \\
\text { Mailed reminder } \\
\text { postcard with } \\
\text { web link } \\
\end{array}$ & $\begin{array}{l}\text { \$5 Prepaid incentive } \\
\text { Two mailed invitation } \\
\text { letters with links } \\
\text { /QR code to web } \\
\text { survey ("hybrid") } \\
\text { Mailed reminder } \\
\text { postcard with } \\
\text { link/QR code to } \\
\text { web survey }\end{array}$ \\
\hline $\begin{array}{l}\text { Total Costs for } \\
\text { Components }\end{array}$ & $\begin{array}{l}\text { Mail: } \\
\text { Postage: } \$ 685.80 \\
\text { Printing/duplication/paper: } \\
\$ 340.00 \\
\text { Envelopes: } \$ 75.00 \\
\text { Labor: } \$ 75.00 \\
\text { Incentives: } 2 \$ 100 \text { gift certificate } \\
\text { Telephone: } \\
\text { Total cost of } \$ 69 \text { for } \\
\text { telephone calls } \\
\text { Total cost for wages } * 8.75 / \text { hour } \\
\text { for data collection tasks }=\$ 350 \\
\text { Labor wages for administrative } \\
\text { tasks for preparing advance } \\
\text { notification packet: } \$ 7.50 / \text { hour } \\
* 4 \text { hours = } \$ 30 \\
\text { Postage costs }=\$ 157.20 \\
\text { Printing/duplication } / \text { paper } \\
=\$ 78.00 \\
\text { Envelopes }=\$ 25.00\end{array}$ & $\begin{array}{l}\text { Mail: } \\
\text { Postage: } \$ 1242 \\
\text { Copying and } \\
\text { printing: } \$ 1383 \\
\text { Mailing database: } \$ 1218 \\
\text { Labor: } 104.5 \text { hours; } \\
\$ 1045 \\
\text { Email: } \\
\text { Email database: } \$ 4332 \\
\text { Hosting web survey } \\
\text { fee: } \$ 500 \\
\text { Mail postcard with } \\
\text { web link } \\
\text { Postage: } \$ 1328 \\
\text { Printing: } \$ 392 \\
\text { Mailing database: } \$ 1218 \\
\text { Hosting web survey } \\
\text { fee: } \$ 500\end{array}$ & Not reported & $\begin{array}{l}\text { Database of all } \\
\text { community pharmacies } \\
\text { and associated } \\
\text { managing pharmacists } \\
\text { in state: } \$ 125 \\
\text { Labor: listed but } \\
\text { unspecified } \\
\text { Mailing supplies: listed } \\
\text { but unspecified } \\
\text { Postage costs: listed } \\
\text { but unspecified }\end{array}$ \\
\hline
\end{tabular}


Table 1 (continued). Survey costs as reported in four Research in Social and Administrative Pharmacy papers.

\begin{tabular}{|c|c|c|c|c|}
\hline & $\begin{array}{l}\text { Westrick and } \\
\text { Mount (2007) }\end{array}$ & $\begin{array}{l}\text { Hardigan, Popvici, } \\
\text { Carvajal (2016) }\end{array}$ & $\begin{array}{l}\text { Schherbakova } \\
\text { (2016) }\end{array}$ & $\begin{array}{l}\text { Agley et al. } \\
\text { (2017) }\end{array}$ \\
\hline $\begin{array}{l}\text { Costs per unit for } \\
\text { components } \\
\text { and overall }\end{array}$ & $\begin{array}{l}\text { Cost per sample unit } \\
\text { Mail: } \$ 1.20 \\
\text { Postage: } \$ 0.60 / \text { pharmacy } \\
\text { = } \$ 0.37 / \text { delivery of survey } \\
\text { packet + } \$ 0.25 \text { stamp on } \\
\text { return survey } \\
\text { Printing: } \$ 0.05 / \text { page } \\
\text { Envelopes and labels: } \$ 75 \\
\text { Labor: } \$ 7.50 / \text { hour for } \\
\text { administrative tasks } * 10 \text { hours } \\
\text { Telephone: } \$ 1.60 \text { (no advance } \\
\text { letter, simulated) } \\
\text { Telephone: } \$ 2.71 \text { (with advance } \\
\text { letter, simulated) } \\
\text { Cost per complete } \\
\text { Mail: } \$ 4.37 \\
\text { Telephone: } \$ 1.99 \\
\text { (no advance letter) } \\
\text { Telephone: } \$ 3.36 \\
\text { (with advance letter) }\end{array}$ & $\begin{array}{l}\text { Mail: } \$ 10.31 \\
\text { Email: } \$ 29.64 \\
\text { Mail postcard with } \\
\quad \text { web link: } \$ 47.10\end{array}$ & Hybrid: $\$ 33.50$ & Hybrid: $\$ 24.67$ \\
\hline
\end{tabular}

40 hours of interviewer time across respondents and nonrespondents $\left(U_{\text {oit }}\right)$. For the telephone surveys, assuming no change in response rate with or without advance letters, the authors estimate a per-unit cost of $\$ 1.66$ and $\$ 1.99$ per complete without advance materials, increasing to $\$ 2.71$ and $\$ 3.36$ respectively with advance materials $\left(C^{E}{ }_{i t} / n, C^{E} i t r\right)$. Thus, under these assumptions, the authors argue that telephone surveys are more cost effective than mail surveys, at least for nonresponse follow-up.

Hardigan, Popvici, and Carvajal, ${ }^{17}$ Shcherbakova, ${ }^{18}$ and Agley et al. ${ }^{19}$ report costs for what all authors call a hybrid design, using postal mail (a postcard or letter with a web link) to recruit respondents to a web survey, a version of a "push-to-web" design used in household surveys ${ }^{20}$ (Hardigan, Popvici, and Carvajal report costs for other designs as well). Although the hybrid design is conceptually similar across these three studies, the costs across these studies vary from $\$ 24.67$ to $\$ 47.10$ to per completed survey $\left(\mathrm{C}_{i t}^{O} / r\right)$. Table 1 reports what components 
(subscripted by $i$ in the typology notation) are included in these costs, which vary over the studies. For instance, Hardigan, Popvici, and Carvajal (2016) and Agley et al. (2017) include the cost of the sample frame in their cost calculations - ranging from $\$ 125$ to $\$ 1218$ (and up to $\$ 4332$ for an email list) $\left(C^{0}{ }_{i t}\right)$. Hardigan, Popvici, and Carvajal (2016) also include the cost of hosting a web survey in their cost calculations $(\$ 500)$, but this is not mentioned in the other studies.

\section{What can we learn from survey costs from pharmacy and other studies?}

A careful reader will note that, across the studies in Table 1, design features vary - for instance, Agley, et al. include an incentive, use letters rather than postcards, and provide QR codes in addition to web links. In addition to the design features listed, the questionnaires vary in length and topic, the sample frames vary, the target populations vary, the response rates vary, and so on. With only four studies, it is impossible to extrapolate what features are driving costs, and what cost features are associated with survey errors. But the problem is not intractable. What can a survey researcher do to contribute to a more general understanding of survey costs?

Two approaches may be fruitful. First, within survey organizations, researchers can build databases of cost metrics and survey design features that may affect costs, and estimate predictive models for monetary and nonmonetary measures of survey costs with these design elements. These predictive models may be able to be shared generally outside the organization. For example, to evaluate whether an increased incentive value reduced interviewing costs, Wagner ${ }^{21}$ uses predictive models relating two nonmonetary measures of costs - interviewer hours and the total number of call attempts. This type of within-study model permits Wagner to examine cost-effectiveness of a design decision even when cost metrics were not recorded in a way that allowed the experimental effects to be easily disentangled. As a nonmonetary metric (hours per interview), the results do not rely on a particular wage structure for interviewers and do not reveal proprietary cost information. Further, the cost savings of 0.3 hours per interview is a convincing argument for increasing incentives from $\$ 40$ to $\$ 60$ in large-scale interviewer administered surveys, the design feature evaluated in Wagner's study. 
To do this kind of study, survey organizations can start by evaluating what kind of cost data are available in record systems. If multiple record systems exist, survey organizations can identify what effort may be needed to link these systems (for instance, some have noted difficulty in linking paradata of call attempts with interviewer timesheets ${ }^{22}$ ). Organizations can also evaluate what units are available over which to assess variation in costs (e.g., sampled households or people, establishments, interviewers, coders, supervisors, strata, counties, or primary sampling units), evaluate processes to link characteristics of these units to costs (e.g., urban versus non-urban areas; large versus small establishments; regions of the country), and then identify how costs vary over these characteristics. The measurement of costs should be treated similar to other evaluations of potential errors in record systems (e.g., interviewers may underreport call attempts, ${ }^{23}$ email tracking for web surveys may not accurately reflect whether the email was opened ${ }^{24}$ ). If information is not available but would be considered useful, cost tracking studies or other methods of eliciting costs may be needed. For example, Vannieuwenhuyze $^{25}$ reports that actual costs for a methodological mixed mode experiment were not possible to obtain from the actual data collection organization's records, and asked for quotes from other organizations to be able to obtain reasonable estimates of fixed and variable costs.

Outside of a survey organization, survey costs could be examined systematically or meta-analytically across published articles, where different cost measures are the outcomes and survey design features are the predictor variables. Given the variation in what components are included in survey cost measures, additional predictors may also need to include the components included in the cost metrics.

\section{Fixed costs: The unexamined cost component}

As noted, one variation across the studies reported in Table 1 is what are considered inputs for variable costs. Hardigan, Popvici, Carvajal (2016) and Agley et al. (2017) include fees for web survey software and/or access to sample frames, costs which other studies may consider to be fixed costs. Fixed costs are an important part of a survey budget, and are commonly included in elementary cost models. For instance, a review of nine common sampling textbooks found that the two most common cost models (for a stratified random sample and for a two-stage equal sized 
cluster sample) include a fixed costs term. ${ }^{10,12,26-32}$ In particular, the costs of a stratified random sample are expressed as $C=C_{0}+\sum_{h=1}^{H} n_{h} C_{h}$. Here, the total cost of a survey is a sum of the fixed costs $\left(C_{0}\right)$ and the cost per element in stratum $h\left(C_{h}\right)$ multiplied by the number of units selected in stratum $\mathrm{h}\left(n_{h}\right)$, added up overall of the $H$ strata. Costs for a two-stage equal-sized cluster sample are expressed as $C=C_{0}+C_{1} a+C_{2} a b$. This formula represents total costs $(C)$ as the sum of total fixed costs $C_{0}$, plus the cost for each cluster $\left(C_{1}\right)$ times the number of clusters selected $(a)$ and the cost for a single element in a PSU $\left(C_{2}\right)$ times the number of clusters $(a)$ times the number of elements selected per cluster $(b)$. Of course, more elaborate cost models exist.

These two cost models, and other similar cost models that appear in survey sampling textbooks, however, are likely the primary (or only!) survey cost models that nascent statisticians encounter during their educational training. Despite the inclusion of fixed costs in cost models, they are not part of the sample design optimization problem that focuses on sample size, with an assumption that fixed costs do not vary with sample size or with variable costs. Furthermore, for a fixed budget, higher fixed costs constrain the total amount available to expend on variable costs and thus constrain the sample size, design decisions available, precision of estimates, and possible contributions of measurement, coverage, and nonresponse errors. Yet few textbooks provide actual examples of fixed costs in examples or in homework problems (only Lohr ${ }^{29,30}$ does this). Many textbooks describe fixed costs as "overhead costs," ${ }^{26}$ Valliant, Dever, and Kreuter (pp. 44-45) provide more detail, stating that "fixed costs ... can include ... salaries for a project manager, programmers, and editing supervisors." ${ }^{12}$ This lack of specificity about fixed costs may lead readers outside of survey organizations to not realize that fixed costs can be a sizable contributor to the total budget of a survey. ${ }^{25,33}$

Yet a growing body of empirical studies that estimate both fixed and variable costs are those making decisions about whether to use a single-mode versus mixed-mode study designs. Some studies use models to extrapolate information on fixed costs without reporting survey organization-specific cost structures. In particular, Vannieuwenhuyze ${ }^{25}$ uses costs solicited from an external organization to estimate fixed and variable costs for a single-mode mail survey, a single-mode faceto-face survey, and a mixed mode mail and face-to-face survey using a 
regression framework, reporting that fixed costs are €14,456, €20,591, and $€ 21,574$ for these designs, respectively, with corresponding variable costs of $€ 18$, €96, and €34 per sample unit. Roberts and Vandenplas $^{33}$ assume a fixed budget of $\$ 100,000$ to report fixed and variable costs. They report that a single-mode mail survey has fixed costs of $\$ 16,461$ and a per-sample unit variable cost of $\$ 22.28$, a sequential web and mail survey has fixed costs of $\$ 14,955$ for the web survey, plus the fixed costs of the mail survey, and a variable cost of $\$ 18.04$ per sample unit, and a combined telephone and mail survey with mail follow-up has fixed costs of $\$ 25,269$ for the telephone component, plus the fixed costs for the mail survey, and a variable cost of $\$ 39.64$ per sample unit. Zuidgeest et al. ${ }^{34}$ report that a single-mode mail survey yielded fixed costs ("general," questionnaire programming and design, and data file processing) that were $€ 10.7$ per completed questionnaire, or $41.7 \%$ of the total costs, compared to $€ 14.0$ per complete for the mixed-mode web and mail survey, or $58.4 \%$ of the total costs. Despite these differences in fixed costs across the modes, the total costs per completed questionnaire was lower for the mixed-mode survey (€23.9 compared to €25.8 for the single-mode mail survey) due to reduced printing, postage, and data entry costs.

These studies show that fixed costs are a sizable part of a survey budget, and that information about fixed costs can be usefully incorporated when making decisions about whether to have multiple modes or single modes of data collection. So, why are fixed costs unreported? For survey organizations, fixed costs may be considered especially proprietary parts of a budget. For academic studies where faculty and graduate students shoulder the role of questionnaire design, sample design and selection, and other development, fixed costs may not be tracked, especially when funding agencies consider these acts to be a normal part of a faculty or student role. For those who contract to a survey company, budget estimates and invoices rarely provide details about how costs are considered, instead providing a lump sum cost estimate or reimbursement amount for conducting the survey. Because "[f]ixed costs of surveys are large and not well identified"13 (p. 5), more research is needed on contributors to fixed costs, variations in fixed costs across study designs, and the relationship between fixed and variable costs. 


\section{Linking costs and errors}

High quality surveys simultaneously try to maximize quality and timeliness within a reasonable cost to do the needed work. An open question is the relationship between quality and cost. Linking survey costs with survey errors is difficult. The most common domain in which cost models are linked to error models is in sample design, where survey costs are included as a constraint when estimating sample size requirements to meet different precision goals. These models do not answer the question about how increased spending on different design features affects possible error structures.

To address the question of the relationship between costs and survey errors, simulation studies have looked at cost-error tradeoffs for mixed mode studies, ${ }^{25}$ incentives, ${ }^{35}$ and adaptive survey design. ${ }^{36}$ These simulations could provide fruitful avenues for future research. Additionally, other empirical studies may be possible through evaluation of existing cost records. For instance, survey researchers or organizations may be able to identify units over which variation in costs is meaningful (e.g., interviewers, primary sampling units, strata, coders), link error indicators to these units (e.g., measures of reliability, deviations of survey estimates from benchmark values), and evaluate the association between these cost measures and error indicators. Finally, meta-analytic approaches to costs and errors could examine whether error indicators systematically vary with costs across different types of study designs. For instance, do surveys with higher per-unit costs have higher or lower response rates? Does this differ by mode of data collection? By length of the questionnaire?

\section{Looking forward to research on costs}

As response rates fall, costs to conduct surveys increase. ${ }^{37,38}$ Despite rising costs, budgets to federal statistical agencies have remained relatively flat over the last decade. Between fiscal year 2012 and fiscal year 2020 in US federal statistical agency budgets, although budgets increased in nominal dollars at ten of the top thirteen federal statistical agencies, ${ }^{39}$ inflation-adjusted ${ }^{40}$ federal statistical agency budgets declined at nine of the largest thirteen agencies. Costs are a major factor behind increased 
calls to replace or augment survey data with administrative records or other existing data sources. ${ }^{38}$ Thus, it is imperative for those who conduct surveys to understand how different cost drivers affect total costs, costs per interview, and errors in coverage, measurement, nonresponse, and post-survey processing.

As argued above, there are many open questions about survey costs. What are major drivers of different costs? Do component-level costs vary over different populations? Over different survey topics? Over different time periods? How are costs for different components costs associated with one another? To what extent are cost drivers associated with error indicators? Exploiting variation in costs over different units - sample units, responding units, interviewers, supervisors, coders, and such - can help with understanding how variation in costs arise as well as what variation in costs are associated with which survey outcomes. Exploiting variation in costs across studies can help with understanding how cost drivers are associated with each other and with error indicators. Use of the Olson, Wagner, and Anderson ${ }^{14}$ cost typology will allow survey researchers to articulate costs in ways that are both useful for understanding and predicting costs as well as associating costs with survey errors.

Survey professionals need to do more than simply acknowledge that survey costs exist. Rather, we need to try to unpack what areas in the current vacuum of knowledge around survey costs can be easily knowable, and strive to have consistent measurement and articulation of these costs across studies and organizations. The path to understanding drivers of response rates required a common set of definitions about respondents and nonrespondents, culminating in AAPOR's Standard Definitions ${ }^{15}$ for survey participation outcomes. Understanding survey costs requires a similar step forward.

Acknowledgments Thanks to James Wagner and Raeda Anderson for collaborations in developing the typology. Thanks to Angelica Phillips and Rachel Stenger for assistance in reviewing sampling textbooks. An earlier version of this paper was presented at the Health Survey Research Methods Conference, Williamsburg, VA, March 2020.

Appendix A. Supplementary data The following is the supplementary data related to this article: "No data was used for the research described in the article." 


\section{References}

1. Biemer PP, Lyberg LE. Introduction to Survey Quality. New York: John Wiley \& Sons, Inc.; 2003.

2. Groves RM. Survey Errors and Survey Costs. New York: John Wiley \& Sons, Inc.; 1989.

3. Wagner J, West BT, Guyer H, et al. The effects of a mid-data collection change in financial incentives on total survey error in the national survey of family growth. In: Total Survey Error in Practice. John Wiley \& Sons, Inc.; 2017:155-177.

4. Olson K, Smyth JD, Horwitz R, et al. Transitions from telephone surveys to selfadministered and mixed-mode surveys: AAPOR task force report. J Survey Stat Methodo. 2020.

5. Kappelhof J. Survey research and the quality of survey data among ethnic minorities. In: Biemer PP, De Leeuw ED, Eckman S, et al., eds. Total Survey Error in Practice. Hoboken, NJ: John Wiley and Sons; 2017:235-252.

6. Draugalis JR, Coons SJ, Plaza CM. Best practices for survey research reports: a synopsis for authors and reviewers. Am J Pharmaceut Educ. 2008;72:11.

7. Bennett C, Khangura S, Brehaut JC, et al. Reporting guidelines for survey research: an analysis of published guidance and reporting practices. PLoS Med. 2011;8, e1001069.

8. Rybakov KN, Beckett R, Dilley I, Sheehan AH. Reporting quality of survey research articles published in the pharmacy literature. In: Research in Social and Administrative Pharmacy. 2020.

9. Groves RM. Survey Methodology. New York: John Wiley \& Sons, Inc.; 2004. 10. Kish L. Survey Sampling. New York: John Wiley \& Sons, Inc.; 1965.

11. Singer E, Hoewyk JV, Gebler N, Raghunathan T, McGonagle K. The effect of incentives on response rates in interviewer-mediated surveys. J Off Stat. 1999;15: 217-230.

12. Valliant R, Dever JA, Kreuter F. Practical Tools for Designing and Weighting Survey Samples. New York: Springer-Verlag; 2013.

13. Karr AF, Last M. Survey Costs: Workshop Report and White Paper. Research Triangle Park, NC: National Institute of Statistical Sciences; 2006.

14. Olson K, Wagner J, Anderson R. Survey costs: where are we and what is the way forward? J Survey Stat Method forthcoming.

15. AAPOR. Standard Definitions: Final Dispositions of Case Codes and Outcome Rates for Surveys. ninth ed. The American Association for Public Opinion Research; 2016.

16. Westrick SC, Mount JK. Evaluating telephone follow-up of a mail survey of community pharmacies. Res Soc Adm Pharm. 2007;3:160-182.

17. Hardigan PC, Popovici I, Carvajal MJ. Response rate, response time, and economic costs of survey research: a randomized trial of practicing pharmacists. Res Soc Adm Pharm. 2016;12:141-148.

18. Shcherbakova N. The delivery mode matters when surveying U.S. practicing pharmacists: the reason to say 'no' to the hybrid method. Res Soc Adm Pharm. 2016; 12:169-170. 
19. Agley J, Meyerson BE, Shannon DJ, Ryder PT, Ritchie K, Gassman RA. Using the hybrid method to survey U.S. pharmacists: applying lessons learned to leverage technology. Res Soc Adm Pharm. 2017;13:250-252.

20. Dillman DA, Smyth JD, Christian LM. Internet, Phone, Mail, and Mixed Mode Surveys: The Tailored Design Method. Hoboken, NJ: John Wiley \& Sons; 2014.

21. Wagner J. Estimation of survey cost parameters using paradata. Survey Practice. 2019;12:no.

22. Wagner J, Olson K. An analysis of interviewer travel and field outcomes in two field surveys. J Off Stat. 2018;34:211.

23. Wagner J, Olson K, Edgar M. The utility of GPS data in assessing interviewer travel behavior and errors in level-of-effort paradata. Survey Res Methods. 2017;11: 218-233.

24. McClain CA, Couper MP, Hupp AL, et al. A typology of web survey paradata for assessing total survey error. Soc Sci Comput Rev. 2019;37:196-213.

25. Vannieuwenhuyze J. On the relative advantage of mixed-mode versus singlemode surveys. Survey Res Methods. 2013;8.

26. Cochran WG. Sampling Techniques. third ed. New York: John Wiley and Sons; 1977. third ed. ed.

27. Levy PS, Lemeshow S. Sampling of Populations: Methods and Applications. fourth ed. Hoboken, NJ: John Wiley \& Sons, Inc.; 2008.

28. Levy PS, Lemeshow S. Sampling of Populations: Methods and Applications. New York: John Wiley \& Sons, Inc.; 1991.

29. Lohr S. Sampling: Design and Analysis. second ed. Boston, MA: Brooks/Cole Cengage Learning; 2010.

30. Lohr S. Sampling: Design and Analysis. first ed. Boston, MA: Cengage Learning; 1999.

31. Särndal C-E, Swensson B, Wretman J. Model Assisted Survey Sampling. New York: Springer-Verlag; 1992.

32. Kalton G. Introduction to Survey Sampling. Newbury Park: SAGE Publications; 1983.

33. Roberts C, Vandenplas C. Estimating components of mean squared error to evaluate the benefits of mixing data collection modes. 2017;33:303.

34. Zuidgeest M, Hendriks M, Koopman L, Spreeuwenberg P, Rademakers J. A comparison of a postal survey and mixed-mode survey using a questionnaire on patients' experiences with breast care. J Med Internet Res. 2011;13:e68.

35. Gelman A, Stevens M, Chan V. Regression modeling and meta-analysis for decision making. J Bus Econ Stat. 2003;21:213-225.

36. Calinescu M, Bhulai S, Schouten B. Optimal resource allocation in survey designs. Eur J Oper Res. 2013;226:115-121. 37. Williams D, Brick JM. Trends in U.S. FaceTo-Face household survey nonresponse and level of effort. J Survey Stat Method. 2018;6:186-211.

38. National Academies of Sciences E, Medicine. Innovations in Federal Statistics: Combining Data Sources while Protecting Privacy. Washington, DC: The National Academies Press; 2017. 
39. FY21 Statistical Agency Budget Developments. American statistical association community science policy. https://community.amstat.org/blogs/stevepierson/2020/02/07/fy21-statistical-agency-budget-developments ; 2020. Accessed May 19, 2020.

40. Statistics USBoL. CPI for all urban consumers (CPI-U). In: Statistics 